\title{
Experimental Characterisation of Hyperelastic Materials for Use in a Passive-Adaptive Membrane on MAVs Wing
}

\author{
RADU CALIN PAHONIE ${ }^{1}$, CIPRIAN LARCO ${ }^{1}$, MIHAI MIHAILA ANDRES ${ }^{1}$, VASILE NASTASESCU ${ }^{1}$, CRISTIAN BARBU $^{1}$, \\ CARMEN LUIZA COSTULEANU2* \\ 1Military Technical Academy, 39-49 George Cosbuc Blvd, 040531, Bucharest, Romania \\ IIon Ionescu de la Brad University of Agricultural Sciences and Veterinary Medicine of lasi, Department of Agrobusiness, \\ 3 Mihail Sadoveanu Alley, 700490, Iasi, Romania
}

\begin{abstract}
The paper focuses on the experimental characterization of hyperelastic of the shelf materials in an effort to implement a membrane skin on a low speed asymmetric wing, in order to assess the benefits of flexible lift surfaces. To better determine the best strain energy function definition for the membrane materials, the most notable hyperelastic constitutive models were used together with experimental uniaxial and equiaxial planar tests. For the experimental equi-biaxial test a special loading device was designed and built in the laboratory. The strain measurements for the experimental tests were conducted using digital image correlation, for increased data precision. From the available constitutive material models taken into account, the best for this application proves to be the Yeoh model, as the experimental strain-stress data has a close match for small as well as large strain values. Numerical simulations using finite elements and the Ansys software were performed to predict the materials behavior.
\end{abstract}

Keywords: hyperelastic material, aeroelastic model, equiaxial rig, Neo-Hookean, Mooney-Rivlin, Yeoh and Odgen model

Small, lightweight, highly maneuverable unmanned air vehicles (UAVs) are the currentfocus of military and civilian research efforts mainly because of their cost efficiency and mission range. From a classification point of view, these types of air vehicles have spans ranging from millimeters to meters, but of particular interest for the current study is the micro class of UAVs, also known as MAVs, with spans never exceeding the $24 \mathrm{~cm}$ limit [1]. The higher goal of the research undertaken in this field by the authors is to develop and test, using a custom designed aerodynamic balance [2] and a low-cost data acquisition system [3], a static aeroelastic model of a passive-adaptive membrane wing to be used on micro scale UAVs. The desirable effects of such a study would be: a better longitudinal static stability of the MAV, higher lift (due to membrane passive deformation), greater understanding of the fluid membrane interaction. The downside of introducing a membrane on the wing: the resulting drag penalty from the constant changing wing shape will not be overlooked [4].

Having briefly summarized the premises of the work, it becomes obvious that the need for deeper understanding of the materials and their properties is quite high. Therefore, this paper is focused on experimental characterization of hyperelastic of the shelf materials.

Latex, silicon, rubber or other such hyperelastic materials have diverse structural applications in the aerospace industry [5]. Their attractiveness is given by the ability to undergo large deformations under small loads, and not sustain considerable permanent deformation when they return to the original shape after the load is alleviated. The modulus of elasticity becomes insufficient to describe the highly nonlinear behavior of such materials.

Hooke suggested a simple linear relation exists between the stress (force) and the strain (deflection). However, the stress-strain behavior of hyperelastic materials differs from Hooke's law in more ways than one.
First, as the latex or rubber deforms under large strains, for the first time, the Mullins effect comes into play. The material goes from being very stiff under the first load to gradually softer, as the load cycles increase. Due to the assumption that the repetitiveness has more meaning in evaluating the behavior of the hyperelastic material, this effect is usually disregarded. The common approach to measuring elastomeric data is to use the engineering stress (the current force divided by the original area) and the engineering strain (the length change divided by the original length). The data presented in this paper will use this type of measures.

Secondly the Hooke's law assumes that stress is proportional to strain, that does not apply for hyperelastic materials because of the obvious differences between their tension and compression behavior. The highly incompressible elastomers determine larger stress values in compression tests, compared to tension under the same order of magnitude strains.

Thirdly, the presence of the viscoelastic effects in hyperelastic materials generates a hysteresis loop when the test repeats under the same strain range. Hysteresis refers to the dissimilar stress-strain relationship during the unloading compared to the loading process. The hyperelastic models presented here, search to determine a single equilibrium curve, and not account for the viscoelastic effects, as they are mostly dependent upon temperature and this specific aerospace application of hyperelastic materials does not involve temperature gradients.

The different sensitivity of the hyperelastic material model constants to different deformation states is the last way in which Hooke's law differs from the hyperelastic laws. Uniaxial, biaxial and planar shear tests with their respective stress-strain responses should be addressed for any research into the behavior of hyperelastic materials $[6,7]$. With the increasingly sophisticated material models 
in need of more experimentally determined constants, data collected from these three modes ensures that no analytical behavior is missed from the experimental point of view.

Hyperelastic materials are characterized by different forms of their strain energy functions. This strain energy is the product of a function that depends on the strain (or stretch ratio) and another function depending on time. We will refer only to the part of the product that depends on strain. Strain is the intensity of the deformation and the assumption under which we can use the constitutive models is that the material is isotropic and elastic.

Common available strain energy functions (SEFs), usually denoted by $W$, are described in terms of the invariants of strain, that is to say as functions of stretch ratios, or even in terms of stretch ratios:

$$
W=f\left(I_{1}, I_{2}, I_{3}\right)
$$

The three strain invariants of the Green deformation tensor, $I_{1}, I_{2}, I_{3}$ can be expressed as:

$$
\begin{aligned}
& I_{1}=\lambda_{1}^{2}+\lambda_{2}^{2}+\lambda_{3}^{2} \\
& I_{2}=\lambda_{1}^{2} \lambda_{2}^{2}+\lambda_{2}^{2} \lambda_{3}^{2}+\lambda_{3}^{2} \lambda_{1}^{2} \\
& I_{3}=\lambda_{1}^{2} \lambda_{2}^{2} \lambda_{3}^{2}
\end{aligned}
$$

in terms of the three principal stretch ratios in the three respective principal directions $\lambda_{1}, \lambda_{2}, \lambda_{3}$. The definition of the stretch ratio, $\lambda$, is the ratio between the deformed and the initial gauge lengths :

$$
\lambda=\frac{l}{l_{0}}=1+\frac{l-l_{0}}{l_{0}}=1+e,
$$

where $\boldsymbol{e}$ is the engineering strain.

Under the further assumption that the hyperelastic material is incompressible $I_{3}=1$, and therefore $\mathrm{W}$ will be a function of $I_{1}$ and $I_{\text {, }}$ only.

Selecting a suitable SEF for a particular purpose depends on the nature of the application as well on the available data for material constant identification [8]. The desired qualities of the hyperelastic material model in order for it to be selected are [9]: a small number of fitting material parameters ensuring a small number of experimental tests; change of deformation mode does not bring about new issues; the entire $S$ shaped response of the material is reproduced; the mathematical formulation is simple; therefore, the numerical implementation is simple as well.

A brief review of the hyperelastic models is considered important to compare and justify the use of one model in place of another in this current work, from the aerospace application perspective $[10,11]$.

\section{A)Neo-Hookean model}

This model can be used for relatively small strains (of up to $30 \%$ ) and its SEF can be described as follows:

$$
W=C_{10}\left(\overline{I_{1}}-3\right)+\frac{1}{d}(J-1)^{2},
$$

where $\boldsymbol{J}$ is the Jacobian and $\boldsymbol{d}$ is the incompressibility parameter.

\section{B)Mooney-Rivlin model}

One of the earliest phenomenological model proposed for nonlinear elasticity that proves to be well versed for moderate to large strains (between 30\% to 200\% depending on the order) under uniaxial elongation and shear deformation, was given by Mooney as [12]:

$$
W=\sum_{m \nu n 0}^{\infty} C_{m n}\left(\overline{I_{1}}-3\right)^{m}\left(\overline{I_{2}}-3\right)^{n}+\frac{1}{d}(J-1)^{2},
$$

with 2, 3, 5 and 9 parameter models raising the number of material constants that can be determined from uniaxial, biaxial and planar tests, as well as increasing the simulation precision. From these models only the implemented 5 parameter Mooney-Rivlin [13] one is described below:

$$
\begin{aligned}
& W=C_{10}\left(\overline{I_{1}}-3\right)+C_{01}\left(\overline{I_{2}}-3\right)+C_{11}\left(\overline{I_{1}}-3\right)\left(\overline{I_{2}}-3\right) \\
& +C_{20}\left(\overline{I_{1}}-3\right)^{2}+C_{02}\left(\overline{I_{2}}-3\right)^{2}+\frac{1}{d}(J-1)^{2},
\end{aligned}
$$

where: $\boldsymbol{J}$ is the Jacobian and $\boldsymbol{d}$ is the incompressibility parameter and $\mathrm{C}_{10}, \mathrm{C}_{01}, \mathrm{C}_{11}, \mathrm{C}_{20}$ and $\mathrm{C}_{02}$ are the material constants.

\section{C) Polynomial model}

For an isotropic and compressible hyperelastic material, the SEF can be expanded as an infinite series of the first and second deviatoric principal invariants $I_{1}$ and $I_{2}$, as follows:

$$
W=\sum_{m n=1}^{N} C_{m n}\left(\overline{I_{1}}-3\right)^{m}\left(\overline{I_{2}}-3\right)^{n}+\sum_{k=1}^{N} \frac{1}{d_{k}}(J-1)^{2 k},
$$

where: $\boldsymbol{d}_{k}$ is the incompressibility parameter and $\mathrm{C}_{\mathrm{mn}}$ are the material constants.

\section{D) Yeoh Model}

Yeoh [14, 15] proposed in 1990 and 1993 a third order polynomial model based on the first invariant I only. This model can simulate diverse modes of deformation with limited experimental data and presents a good fit over a large strain range. It has the following general form:

$$
W=\sum_{i=1}^{N} C_{10}\left(\overline{I_{1}}-3\right)^{i}+\sum_{i=1}^{N} \frac{1}{d_{i}}(J-1)^{2 i}
$$

\section{E)Odgen model}

Odgen [16] proposed in 1972 another phenomenological model based on the principal stretches rather than on the invariants. The following form is able to model accurately large ranges of deformations (up to 700\%) if there is available sufficient experimental data:

$$
\left.W=\sum_{i=1}^{N} \frac{2 \mu_{i}}{\alpha_{i}^{2}} \overline{\lambda_{1}^{a_{i}}}+\overline{\lambda_{2}^{\alpha_{i}}}+\overline{\lambda_{3}^{\alpha_{i}}}-3\right)+\sum_{i=1}^{N} \frac{1}{d_{i}}(J-1)^{2 i}
$$

where $\overline{\lambda_{i}}$ is the deviatoric principal stretch, $\boldsymbol{d}$ is the incompressibility parameter and $\mu_{i}, \alpha_{i}$ are the material properties that depend upon the temperature.

\section{Experimental part}

Material

The tested material was an off the shelf latex product with a chemical composition based on natural rubber.

Table 1 shows a comparison between the mechanical properties of natural rubber and other materials used in the aerospace industry.

\section{Mechanical testing}

Noteworthy are the differences between the standardized test methods and the experimental requirements for hyperelastic materials. Standard organizations at national or international level have yet to properly define all of the appropriate experiments that can help to clearly identify the nonlinear and incompressible attributes of hyperelastic materials.

Therefore, the testing done during this research meets the input requirements for the Ansys software implemented hyperelastic material models. All the experimental data was used as a set, even though it 
Table 1

MECHANICAL PROPERTIES OF MATERIALS COMPARISON

\begin{tabular}{|c|c|c|c|c|}
\hline Material & $\begin{array}{c}\text { Young's } \\
\text { Modulus } \\
(\mathbf{M P a})\end{array}$ & $\begin{array}{c}\text { Bulk } \\
\text { Modulus } \\
(\mathbf{M P a})\end{array}$ & $\begin{array}{c}\text { Shear } \\
\text { Modulus } \\
\mathbf{( M P a )}\end{array}$ & $\begin{array}{c}\text { Poisson's } \\
\text { Ratio }\end{array}$ \\
\hline Rubber & $0.76-7.6$ & $3,000-$ & $0.35-$ & $\sim 0.50$ \\
\hline $\begin{array}{c}\text { Aluminum } \\
\text { Alloys }\end{array}$ & 69,116 & 67,733 & 23,499 & 0.31 \\
\hline Mild Steel & 207,348 & 158,967 & 79,483 & $0.29-0.3$ \\
\hline
\end{tabular}

pertains to a certain strain state corresponding to a certain type of experiment.

\section{Equiaxial apparatus and test}

These experiments focused on inducing a constant stress and strain around the sides of a hyperelastic disc and create an equiaxial state of stress and strain that is independent of the samples thickness or radial position.

The apparatus introduces the load through 16 small grips attached to the perimeter of the hyperelastic disc under spring clamps. Outward radial pulling movement generates the straining of the elastomer by means of metallic strings, pulleys and a loading metal disc. In the center of the loading metal disc a steel rod is fitted, on which calibrated weights introduce the load. To ensure the same tension is found in every load transferring metallic string, the adopted solution was to use guitar strings and tune them all to vibrate on the same note. This way the same tension is assured on every one of the 16 radial loading directions (fig. 1).

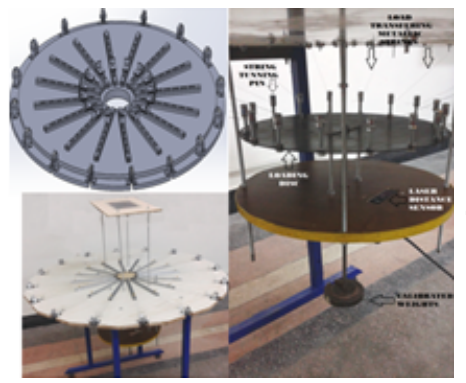

Fig. 1. CAD designed biaxial experimental rig, side view and bottom loading fixture

A laser sensor is fitted on a wooden platform underneath the loading metal disc, measuring the distance $\boldsymbol{d}_{\text {in }}$ that the metal disc travels down, with a precision of $0.06 \mathrm{~mm}$. This distance is used to calculate the total force acting on the specimen. The shape of the tested specimens is presented in figure 2.

One can observe that there are radial cuts on the specimen. They serve the purpose of removing any tangential forces betw een the clamps. The clamps are not attached to the side of the specimen and by gripping the specimen from top and bottom they prevent the free flowing of the material. Also at the end of the radial cuts, small perforated circular cuts prevent the forming of stress concentrators and delay the tearing of the specimen.

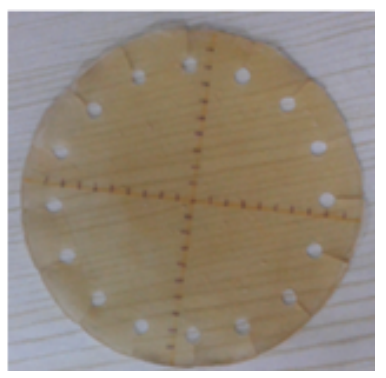

Fig. 2. Specimen with radial cuts, perforated stress relievers and $5 \mathrm{~mm}$ perpendicular markings

\section{Strain measurement}

The strain on the surface of the specimen disc is measured via digital image correlation with a high resolution camera placed on a stable platform $500 \mathrm{~mm}$ away from the specimen. However, because of the strain field induced by the clamps, the possible compliance in the loading guitar strings and the material flowing generated by the gripping, the relation between the strain in the specimen's center area and the distance that the clamps are travelling is not known with certainty. That's why it is important not to add other constrains on the specimen and use non-contact measuring techniques.

\section{Force measurement}

At any moment, the force acting on the hyperelastic disc is:

$$
F_{i}=\frac{G_{i}}{n \cdot \sin \alpha_{i}},
$$

where: $\boldsymbol{G}_{\boldsymbol{i}}$ is the introduced load, $\boldsymbol{n}$ is the number of tensile directions and $\alpha_{i}$ is the angle between the wire and the metal disc.

For each weight increment, the angle can be determined by measuring the metal disc displacement (fig. 3):

$$
\tan \alpha_{i}=\frac{d_{i}}{R},
$$

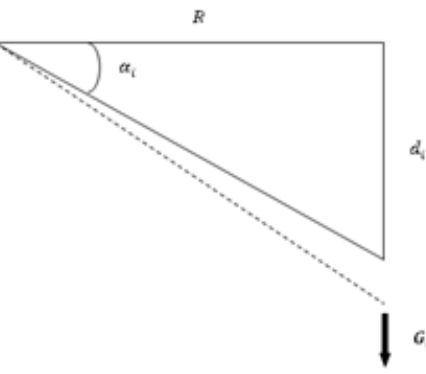

Fig. 3. Sketch of

4. experimental device loading angle deviation

The equiaxial stress on the center area of the hyperelastic disc is calculated using the following formula:

$$
\sigma=\frac{F}{\pi \cdot D_{i} \cdot h},
$$

where: $\boldsymbol{D}$ is the inner diameter, measured between the punched holes, $\boldsymbol{F}$ is the sum of the radial forces, $\boldsymbol{h}$ is the specimens thickness and $\sigma$ is the engineering stress.

The travelling distance of the loading disc was measured with a laser distance sensor, with a measuring range of 30 to $130 \mathrm{~mm}$ and a resolution of $0.006 \mathrm{~mm}$ at $<10 \mathrm{~ms}$ response time. All the data was collected via an 8 input, 14bit, multifunction data acquisition board, NI USB-6009. The data was then processed using a Mathcad in-house written program.

\section{Finite element simulation using Ansys}

The equiaxial specimen was also simulated in the Static Structural module of Ansys. The specimen's geometry was designed in Solidworks and imported in Ansys. With 57348 elements and 102163 nodes the specimen's meshing was automatically meshed with tetrahedral elements over its entire body. The loading force was distributed over 16 side faces with magnitudes ranging from $1.983 \mathrm{~N}$ to $7.676 \mathrm{~N}$ according to the experimental loading data (fig. 4). The reference values for stress and strain were considered for every load and generated over the graph for stress and strain obtained experimentally for comparison. 


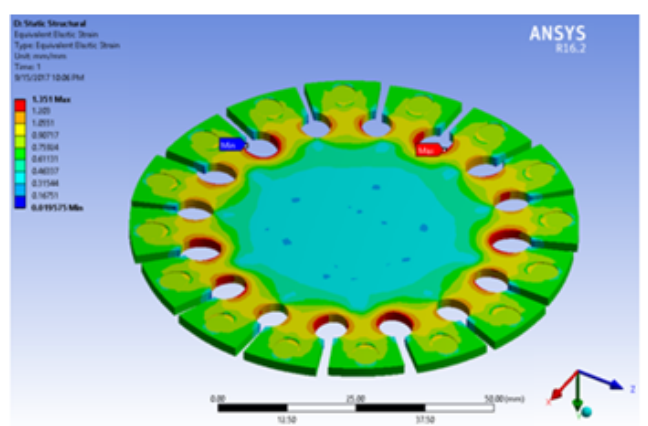

Fig. 4. FEM modeled hyperelastic sample and strain distribution for biaxial loading

\section{Results and discussions}

Five hyperelastic latex specimens with $100 \mathrm{~mm}$ in diameter were tested in the biaxial testing rig. The values obtained as voltage from the laser distance sensor were transformed in $\mathrm{mm}$ through caliper calibration.

Experimental results and curve fitting are provided below for the same sample tested twice (fig.5) and for sample 5 (fig. 6) an interpolation was computer generated to underline the hyperplastic material corresponding curve form.

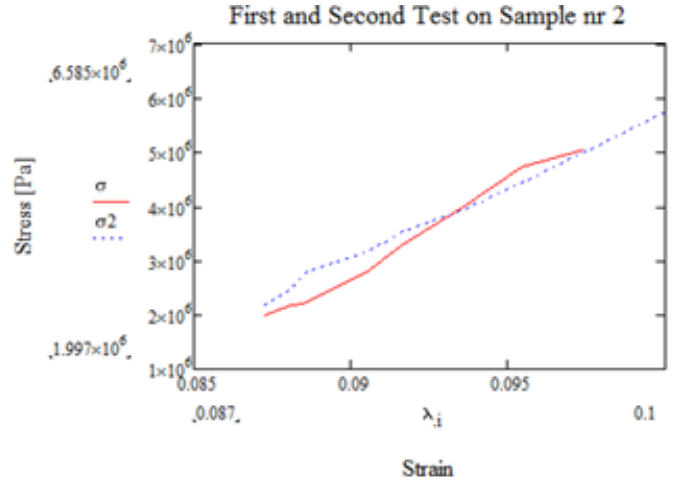

Fig. 5. Graph centered on relevant data points showing the strain differences on the second loading with the same weight of sample no. 2

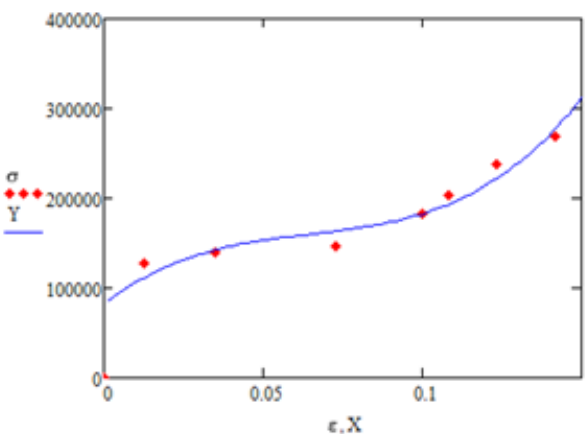

Fig. 6. Stress [Pa] -strain graphed interpolation of experimental data points

Table 2

MOONEY-RIVLIN 2 PARAMETER MATERIAL MODEL COEFFICIENTS

\begin{tabular}{|c|c|c|}
\hline $\mathbf{C}_{10}(\mathbf{M P a})$ & $\mathbf{C}_{01}(\mathbf{M P a})$ & $\mathbf{D}_{1}$ \\
\hline-5.491 & 4.8594 & 0 \\
\hline
\end{tabular}

Table 3

MOONEY-RIVLIN 5 PARAMETER MATERIAL MODEL COEFFICIENTS

\begin{tabular}{|c|c|c|}
\hline $\mathbf{C}_{10}(\mathbf{M P a})$ & $\mathbf{C}_{01}(\mathbf{M P a})$ & $\mathbf{C}_{20}(\mathbf{M P a})$ \\
\hline-171.77 & 161.05 & -399.41 \\
\hline $\mathbf{C}_{11}(\mathbf{M P a})$ & $\mathbf{C}_{02}(\mathbf{M P a})$ & $\mathbf{D}_{1}$ \\
\hline 284.52 & -32.37 & 0 \\
\hline
\end{tabular}

Table 4

NEO-HOOKEAN MATERIAL MODEL COEFFICIENTS

Table 5

ODGEN $3^{\text {RD }}$ ORDER PARAMETER MATERIAL MODEL COEFFICIENTS

\begin{tabular}{|c|c|c|}
\hline $\mathbf{M U 1}$ & $\mathrm{A} 1(\mathrm{MPa})$ & $\mathrm{MU}^{2}$ \\
\hline $\mathbf{7 7 9 . 3 6}$ & 53.342 & 779.4 \\
\hline $\mathbf{A 2}$ & $\mathbf{M U 3}$ & $\mathbf{A 3}^{-3}$ \\
\hline $\mathbf{5 3 . 5 7 9}$ & 779.41 & $53.555^{-3}$ \\
\hline
\end{tabular}

Table 6

YEOH $3^{\text {RD }}$ ORDER PARAMETER MATERIAL MODEL COEFFICIENTS

\begin{tabular}{|c|c|c|}
\hline $\mathbf{C}_{10}(\mathbf{M P a})$ & $\mathbf{C}_{20}(\mathbf{M P a})$ & $\mathbf{C}_{30}(\mathbf{M P a})$ \\
\hline $\mathbf{- 0 . 6 1 0 1 2}$ & 7.0668 & -14.01 \\
\hline
\end{tabular}

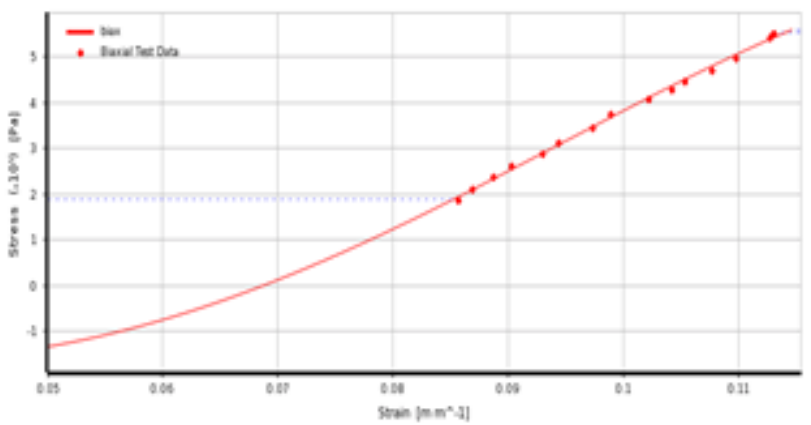

Fig. 7. Chart of properties Yeoh $3^{\text {rd }}$ order

\section{FE simulation results}

Ansys employs a material curve fitting capability that compressibility constants $D_{\text {i. }}$ for different material models used. The test data for the blaxial test was introduced and some hyperelastic material models were fitted on the experimental data provided. From all the models used, naming here Neo-Hookean [12], Mooney-Rivlin [13], Yeoh $[14,15]$ and Odgen [16], the last one was the best choice for latex behavior predictability ( fig. 7) due to its small and large strain data point matching. The coefficients for the previously named material models used in this study are presented in table 2 to table 6 .

The latex, silicon and rubber structures are recommended materials to be intensively used for various high performance fields [17-21].

The environmental pressure could be reduced and human equilibrium enhanced through the extensive use of wasted materials around us [22-35].

\section{Conclusions}

The aim of this article is to offer an experimental and numerical characterization of latex hyperelastic specimens using a custom built biaxial testing machine. After the experimental data is obtained, a numerical study using ANSYS 16.0 is taken to calibrate hyperelastic model coefficients for the given latex behavior.

The novel approach is offered through the designed low state needed for the testing of latex based materials.

Several tests were conducted on a number of specimens that were cut from the same latex sheet to characterize their properties and mechanical behavior. allows the determination of the shear constants $C$ and the cost experimental device that aims at obtaining a pure strain 
The experimental values obtained are used in an ANSYS software simulation with finite elements of the latex sample. Curve fittings are generated using different material models out of which the Yeoh $3^{\text {rd }}$ order material model is considered the best choice for the current application due to the expected membrane deformation of only $30 \%$ after mounting iton the wing. The deformations of the fem modeled latex sample are checked for consistency with the experimental data and the results are within the $10 \%$ RMS error boundary (7.9\%)

This paper proposed an equiaxial experiment of a hyperelastic latex specimen on a custom made device and it does obtain a pure strain state required by any hyperelastic models. However, it is imperative to mention that the errors given by the approximations on the boundary conditions though small are consistent. This directly opposes the uniaxial compression tests where the generated errors are caused by friction.

Future work will consist of latex membrane wing mounting using spray adhesive and considering two possible scenarios: a slack or a tight membrane, and its subsequent behavior characteristics.

\section{References}

1. SHYY, W., IFJU, P., VIIERU, D., Applied Mechanics Reviews, 58, no. 4, 2005, p.283.

2. PAHONIE, R.C., STEFAN, A., COSTULEANU, C.L., BOLDUREANU, D., ANDRUSEAC, G.G., Mat. Plast., 54, no. 1, 2017, p. 155.

3. MIHAI, R.V., MIHAILA-ANDRES, M., ROSU, P.V., PAHONIE, R.C., NEGRU, A., MTA Review, 16, no. 4, 2016, p. 369.

4. MIHAILA-ANDRES, M., ROSU, P.V., LARCO, C.M., PAHONIE, R.C., 8th International Conference on Mechanical and Aerospace Engineering, Prague, Czech Republic, 978-1-5386-3304-5/IEEE, 2017, D 0 I: 10.1109/ ICMAE.2017.8038669.

5. ALI, A., HOSSEINI, M., SAHARI, B.B., American J ournal of Engineering and Applied Sciences, 3, no. 1, 2010, p. 232.

6. JONES, D., TRELOAR, L., J. Phys. D Appl. Phys., 8, no. 11, 1975, p. 1285.

7. MANEA, L.R., CRAMARIUC, B., CAUNII, V., SANDU, I., Mat. Plast., 52, no. 1, 2015, p. 82.

8. KHAJ EHSAEID, H., ARGHAVANI, J , NAGHDABADI, R., Eur. J. Mech. ASolids, 38, 2013, p. 144.

9. CHAGNON, G., MARCKMANN, G., VERRON, E., Rubber Chem. Technol., 77, no. 4, 2004, p. 724.

10. ASTM D638, Standard test method for tensile properties of plastics, 2002.

11. SHAHZAD, M., KAMRAN, A., SIDDIQUI, M., FARHAN, M., Mat. Res., 18, no. 5, 2015, p. 918.

12. MOONEY, M.A., J. Appl. Phys., 11, no. 9, 1940, p. 582.
13. RIVLIN, R.S., Phil. Trans. Royal Soc. London A, 240, no. 822, 1948, p. 459.

14. YEOH, O.H., Rubber Chem. Technol., 66, no. 5, 1993, p. 754.

15. YEOH, O.H., Rubber Chemistry and Technology, 63, 1990, p. 792. 16. OGDEN, R.W., Proceedings of the Royal Society of London. Series A, Mathematical and Physical Sciences, 326, no. 1567, 1972, p. 565.

17. DUMITRU, P., JITARIU, I., Mat. Plast., 48, no. 1, 2011, p. 64.

18. DESELNICU, D.C., MILITARU, G., DESELNICU, V., Mat. Plast., 51, no. 1, 2014, p. 72.

19. SEBESAN, I., ZAHARIA, N.L., SPIROIU, M.A., FAINUS, L., Mat. Plast., 52, no. 1, 2015, p. 93.

20. PRICOP, M., BALESCU, H., ROSU, S., URECHESCU, H., CRAINICEANU, Z., Mat. Plast., 53, no. 1, 2016, p. 79.

21. SACARESCU, L., Mat. Plast., 46, no. 1, 2009, p. 43.

22. HANCU, L.L., COMSA, S., Mat. Plast., 48, no. 4, 2011, p. 336.

23. PAHONIE, R.C., STEFAN, A., ADOCHIEI, I.R., COSTULEANU, C.L., ANDRUSEAC, G.G., UNGUREANU, G., SARDARU, D.P., Mat. Plast., 54, no. 2, 2017, p. 396.

24. IGNAT, G., COLIBABA, C., COSTULEANU, C.L., MORARU, I., VINTU, C.R., UNGUREANU, G., BEJ INARIU, C., Mat. Plast., 54, no. 3, 2017, p. 586.

25. ANDRUSEAC, G.G., PASARICA, A., BREZULEANU, C.O., IGNAT, G., BREZULEANU, S., COSTULEANU, C.L., Rev. Chim. (Bucharest), 68, no. 6, 2017, p. 1357.

26. IGNAT, G., COLIBABA, C., COSTULEANU, C.L., BALAN, A., ROTARU, L., SANDU, I.C.A., Mat. Plast., 53, no. 3, 2016, p. 367.

27. IGNAT, G., BALAN, G., SANDU, I., COSTULEANU, C.L., VILLE, S.T.S., Rev. Chim. (Bucharest), 67, no. 8, 2016, p. 1560.

28. COSTULEANU, C.L., BOBITAN, N., DUMITRESCU, D., Environ. Eng. Manag. J., 14, no. 6, 2015, p. 1423.

29. COSTULEANU, C.L., DUMITRESCU, D., BREZULEANU, S., BOBITAN, N., Rev. Cercet. Interv. Soc., 48, 2015, p.50.

30. COSTULEANU, C.L., VINTU, C.R., ROBU, D.A., IGNAT, G., BREZULEANU, S., Rev. Chim. (Bucharest), 66, no. 5, 2015, p. 743.

31. COSTULEANU, C.L., BREZULEANU S., IGNAT, G., BOLDUREANU, G., TOMA, M.C., ANDRUSEAC, G.G., Rev. Chim. (Bucharest), 67, no. 10, 2016, p. 1990.

32. COSTULEANU, C.L., BOLDUREANU, G., ANDRUSEAC, G.G., Rev. Chim. (Bucharest), 68, no. 5, 2017, p. 1058.

33. UNGUREANU, G., IGNAT, G., BOGHITA, E., COSTULEANU, C.L., VINTU, C.R., BODESCU, D., BEJ INARIU, C., Rev. Chim. (Bucharest), 68, no. 10, 2017, p. 2350.

34. COSTULEANU, C.L., IGNAT, G., BREZULEANU O., UNGUREANU, G., ROBU, D., VINTU, C.R., BOGHITA, E., BREZULEANU, S., Rev. Chim. (Bucharest), 68, no. 11, 2017, p. 2597.

35. UNGUREANU, G., BOGHITA, E., IGNAT, G., COSTULEANU, C.L., SANDU, A.V., BEJ INARIU, C., VINTU, C.R., Rev. Chim. (Bucharest), 68, no. 11, 2017, p. 2662.

Manuscript received: 8.07.2017 